Research Paper:

\title{
Long-term Marital Satisfaction: Couples' Narratives of the Role of Mate Selection
}

\author{
Maryam Jamalnik $^{1}$ (D), Mohammad Reza Falsafinejad ${ }^{2 *}$ (D), Anahita Khodabakhshi-Koolaee ${ }^{3}$ (D) \\ 1. Department of Counseling, Faculty of Humanities and Social Sciences, Science and Research Branch, Islamic Azad University, Tehran, Iran \\ 2. Department of Assessment and Measurement, Faculty of Psychology and Educational Sciences, Allameh Tabataba'i University, Tehran, Iran. \\ 3. Department of Psychology and Education Sciences, Faculty of Humanities, Khatam University, Tehran, Iran.
}

\begin{tabular}{|c|c|}
\hline $\begin{array}{l}\text { Use your device to scan } \\
\text { and read the article online }\end{array}$ & Crtation: Jamalnik M., Falsafinejad, M. R., \& Khodabakhshi-Koolaee, A., 2020. Long-term Marital Satisfaction: Couples' \\
\hline 口ifirita & $\begin{array}{l}\text { Narratives of the Role of Mate Selection. Journal of Client-Centered Nursing Care, 6(4), pp. 267-276. https://doi.org/10.32598/ } \\
\text { JCCNC.6.4.337.1 }\end{array}$ \\
\hline apist & doi'https://doi.org/10.32598/JCCNC.6.4.337.1 \\
\hline
\end{tabular}

Article info:

Received: 07 Jan 2020

Accepted: 16 May 2020

Published: 01 Nov 2020
Keywords:

Marital relationship, Couples, Mate selection, Qualitative research

\begin{abstract}
A B S T RA C T
Background: Long-term marital satisfaction depends on various factors in couples' lives. Shared interests, beliefs, and goals can guarantee couples' long and satisfying relationships. However, mate selection is one of the primary requirements for establishing a marital relationship in both modern and traditional societies. Based on the narratives of couples, the present study aimed to explore the role of mate selection in marital satisfaction.

Methods: This study employed a qualitative narrative research design. The participants were couples who lived together at least for 10 years, were satisfied with their married life, and had children. They were selected through the purposive sampling method from the family entertainment centers of health houses affiliated with Qom Municipality, in 2019. The data were generated using in-depth in-person interviews. After interviewing 13 couples, theoretical saturation was obtained. The data were recorded, transcribed, and analyzed manually using the textual analytic approach.

Results: The analysis of the participants' narratives showed that the couples believed that four main themes, including spouse personality traits, shared religious beliefs, shared socioeconomic positions, and mutual respect and understanding affected their marital satisfaction.

Conclusion: The couples who were satisfied with their marriage believed that realistic and correct mate selection played a vital role in the survival and stability of their marital life. It is very important to pay attention to the role and conditions of mate selection and its impact on the stability of marriage. Results from this study help counselors, couples' therapists, mental health professionals, psychiatric nurses, and midwifery consultants prepare couples for premarital programs.
\end{abstract}

* Corresponding Author:

Mohammad Reza Falsafinejad, PhD.

Address: Department of Assessment and Measurement, Faculty of Psychology and Educational Sciences, Allameh Tabataba'i University, Tehran, Iran Tel: +98 (912) 4089785

E-mail: falsafinejad@atu.ac.ir 


\section{Highlights}

- Marital satisfaction is a basic necessity for a lasting married life.

- One of the main causes of divorce and separation is the lack of satisfaction and happiness in living together.

- In this study, researchers examined the role of mate selection in the satisfaction of marriage by examining the narratives of couples who have been married for more than a decade.

- Interviews resulted in four main themes, including spouse personality traits, shared religious beliefs, shared socioeconomic positions, and mutual respect and understanding.

\section{Plain Language Summary}

Mate selection is one of the first requirements for establishing a marital relationship in both Western and non-Western societies. Research shows that lasting marital satisfaction depends on the similarity between a couple's values, culture, religion, personality traits, and economic status. This research focused on mate selection as one of the main factors associated with lasting marital satisfaction. The analysis of the couples' comments showed that the "mate selection" has the main role in their lasting marital satisfaction. Interviews led to four main subjects: spouse personality traits, shared religious beliefs, shared socioeconomic positions, and mutual respect and understanding. The findings of this study help counselors, couples' therapists, mental health professionals, psychiatric nurses, and midwifery consultants prepare couples for premarital programs.

\section{Introduction}

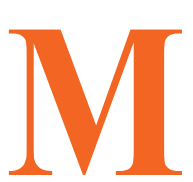

any studies have shown that mate selection is one of the most important decisions that people make in their lives (Abdullah 2018; Buss et al., 2001; Neustadter 2011). This is an important decision so that taking it correctly can form a supportive and emotional family environment, also, such a right decision has many social and economic benefits for people (Guner, Kulikova \& Llull 2017). However, if the spouse is selected incorrectly, it will adversely affect marital satisfaction, leading to harm and psychological disorders, such as less general health, physical illnesses, and emotional disorders like alcohol abuse (Memarzadeh, Khodabakhshi-koolaee \& Khatiban 2017). Despite the significance of mate selection and its profound effects, many pieces of evidence point to the family conflicts and the increased rates of divorce. Accordingly, one of the most important reasons behind couple conflicts is the lack of sufficient knowledge and deliberation when choosing a spouse (Zaheri et al., 2016).

Previous studies have shown that long-term marital satisfaction requires adequate knowledge of each other and resilience to life stressors. For instance, Cheung showed that long-term marital satisfaction is a protective factor in the adjustment of immigrant couples. Factors that have contributed to marital adjustment and the long life of immigrant couples in Canada were: 1. Adjustment to post-immigration change; 2 . Increased intimacy and mutual trust in the couple's marital relationship; and 3. Conflict management and dispute resolution (Cheung, 2008). Moreover, marital satisfaction in three cultures of England, Hong Kong, and China depended on factors, such as a stable relationship with the spouse, spousal support, partnership with the spouse, and the absence of family financial problems (Wong \& Goodwin 2009). Overall, research suggested that the childhood experiences of family relationships, personality traits, new values, education, and employment influenced mate selection (Brooks \& Moore 2020; Holland 2009).

People may have long-term marital satisfaction for a variety of reasons, such as closeness, intimacy, commitment, independence in decision-making, and paying attention to each other's needs (Valentine et al., 2020; Rodríguez-González et al., 2016). Furthermore, couples who have long-term marital satisfaction remember many common positive and negative stories together (Alea, Singer \& Labunko 2015). Besides, the stability of marriage depends on social, cultural, sexual, religious, and financial factors (Macriver \& Dimkpa 2012). However, the role of culture should be considered in choosing a spouse and the stability of married life. For example, a cross-sectional study in Pakistan compared marital sat- 
isfaction among men and women, based on traditional and modern marriages. The results showed that men and women whose spouses had been approved by their parents experienced a higher level of marital satisfaction than couples who married without their parental consent and acceptance (Arif \& Fatima 2015).

Besides, an intercultural study on long-term marital satisfaction in three Muslim-majority countries of Iran, Pakistan, and Turkey showed that kindness, reliability, attractiveness, gender, economic status, resources, education, intelligence, religiosity, and chastity were among the most important factors associated with mate preferences. Although the three countries culturally differed, spousal kindness and trustworthiness were the same key features of mate selection in these countries (Atari, Chaudhary \& Al-Shawaf 2020).

Previous studies on long-term marital stability and satisfaction have addressed two different issues. First, they sought to discover the factors affecting the stability of marriage (Lehrer \& Chen 2013; Igbo, Grace \& Christiana 2015). Second, these studies have addressed the role of mate selection in predicting the success of marriage (Atari, Chaudhary \& Al-Shawaf 2020).

Although numerous studies have addressed the effect of mate selection on a couple's future life, the present study intends to examine the narratives of Iranian couples who have had a long and satisfying married life. In particular, it examines the role of life experiences and spouse selection in marital satisfaction. The focus on life narratives as a research method is a way to deeply understand the human experiences of different events whereby the events grow into a unity of meaning and time (Wells 2011). Narrative research has not yet been used to explore the life stories of Iranian couples who have led long and satisfying marital lives. Therefore, this study aimed to investigate long-term marital satisfaction based on the Iranian couples' narratives of the role of mate selection.

\section{Materials and Methods}

This qualitative study was conducted using a narrative research approach. Narrative research has been defined as "a qualitative design to report an interesting story about the personal experiences of an individual" (Cresswell \& Báez 2020). Narrative research is an approach to study events that occur in human life. It shows how individuals perceive what is happening to them and others. Polkinghorne describes "narrative research as the study of stories" (Polkinghorne 2007), arguing that the main way to truly understand human experience is to pay at- tention to the stories or narratives that people tell about themselves and others. People tell stories that show how they react and make sense of life events (Polkinghorne 2007). Therefore, in narrative research, the stories that people tell are used as the main source of data.

This narrative study was conducted using a social constructionist approach (Polkinghorne 2007), regarding two reasons. First, this approach can be used to examine the participants' experiences and stories of marital satisfaction from different perspectives and how the participants' narratives help them to understand the role of mate selection in the stability of marriage. Second, this approach helps to explore the effects of social and cultural factors on the formation of people's narratives.

The present study focused on the experiences and narratives of couples to reveal the role of mate selection in long-term marital satisfaction. The participants were selected from couples who had lived together for 10 years, were satisfied with their marriage, and had children. The couples were selected through the purposive sampling method from the family entertainment centers of health houses affiliated with Qom Municipality, in 2019. The data were collected using in-depth in-person interviews. Theoretical saturation was obtained after interviewing 13 couples. The inclusion criteria were being married for at least 10 years, marital satisfaction, and having at least one child. The questions asked in the interviews explored the experiences and narratives of the participants. The examples of the questions were "How did you get to know your spouse?" and "How well did you know each other before marriage?".

When answering the questions, the participants had the chance to reflect on the questions, also, no elicitation or stimulation was used. Thus, the participants were free to express their thoughts and feelings without biased opinions. Besides, they were asked for clarification when there was something ambiguous in their conversations. The questions asked for further clarification were extracted from the participants' statements so that their opinions were not influenced or oriented to another subject. At the end of each interview, the participants were asked if they had anything else to say about the topic. During the interviews, in addition to the participants' statements, their body posture and tone of voice were carefully considered, because the use of nonverbal cues when making statements is one of the most important ways to recognize significant statements in the emerging world of a person. Moreover, the researcher tried to establish rapport with the participants, at the beginning of each interview. Each interview lasted for 45 to 
60 minutes, and all interviews lasted 1040 minutes in total. The interviews were conducted in the counseling room of the health house of Qom Municipality from July to October 2019. Figure 1 shows the steps for conducting the study.

All interviews were recorded. This allowed the word-forword transcription of the content of the interviews to be used for further analysis. In addition to the transcription, the participants' gestures and nonverbal cues, such as tone of voice, laughter, and pause were taken into account. Then, the interviews were listened to repeatedly and transcribed.

After recording and transcribing the interviews, the participants' stories were read frequently to get familiar with the whole stories and the narratives within them. The collected data were analyzed using the textual analytic approach (Gee 1991). This approach consisted of five steps: 1. Recording and transcribing the interviews word for word; 2. Separating the narration from the non-narrative text; 3. Performing the initial analysis and extracting general themes from the text; 4. Selecting and analyzing a small number of narrations that are well described and have the most theoretical significance, using the approach proposed by Gee; and 5. Analyzing the transcribed narratives in terms of interpersonal contexts and discourses and extracting the main themes (Gee 1991; Wells 2011).

The validity threats particular to narrative research relate to two areas: "the differences in people's experienced meaning and the stories they tell about this meaning" and "the connections between storied texts and the interpretations of those texts" (Polkinghorne 2007). To overcome these threats and retain validity, a copy of the transcripts was submitted to the participants, and they were asked to check their accuracy and whether there was any inconsistency to be removed. To ensure credibility, the findings were peer checked by professors experienced in narrative research, including a psychologist and two psychiatric nurses. To check the confirmability, the researcher tried not to involve her assumptions in the process of data collection and analysis as much as possible. Figure 1 displays the steps taken to conduct the study.

\section{Results}

The study participants included 13 couples; Table 1 reports the demographic data of the study participants. Also, factors involved in the participants' marital satisfaction were categorized into four main themes, including spouse personality traits, shared religious beliefs, shared socioeconomic positions, and mutual respect and understanding.

\section{The first theme: Personality traits}

The participants narrated their stories about the personality traits of the spouse before marriage. They considered that the spouse's personality traits were involved in the continuity and stability of their marriage and ultimately marital satisfaction. For example, one participant stated, "Before marriage, my wife's characteristics were very important to me because I read psychology books and I knew that intellectual and cognitive maturity is very important in having a stable life". His wife also added, "Yes, by the way, when we just met he said how important this issue was, and interestingly, I was thinking about it a lot. The intellectual maturity for marriage involves managing emotions and responding effectively to the situation. Before and after marriage, this issue was very important for us. We talked about it occasionally and we tried to understand it" (couple \#2).

The participants' narratives also highlighted patience and self-sacrifice. For example, one of the male participants stated, "Self-sacrifice involves taking into account the needs of the other party in addition to your own needs. People with this personality trait do not focus solely on their own needs and pay attention to the needs of others too. When I met my wife, I was interested in her patience as it was important to me". His wife also stated, "Resilience is a person's strength in the face of difficult mental conditions. Highly resilient people are better able to cope with difficult situations. I knew that I was a tolerant person and I could overcome difficulties, and I knew I could endure the toughest hardships. I knew, for example, that my husband was unemployed and he had not finished his studies yet. But I had come to terms with him" (couple \#3).

Moreover, supportiveness, having a sense of responsibility, and kindness were other personality traits pointed out frequently by the participants in their narratives. One of the male participants narrated, "When we met, my wife was a student, and doing her studies was very important to her, and she asked me to let her finish her studies. I also started studying and tried to motivate her. We even attended some classes together and this further motivated her". His wife also pointed out, "Yes, it was really important for me to study, and when we first met each other, I told him about it, and he accepted and helped me a lot. He also had a sense of responsibility. On many occasions in our marital life, he tried to do some of the housework. Of course, this was a joint feature, and it was very important for both of us to be supportive and responsible and to be kind to each other" (couple \#11). 


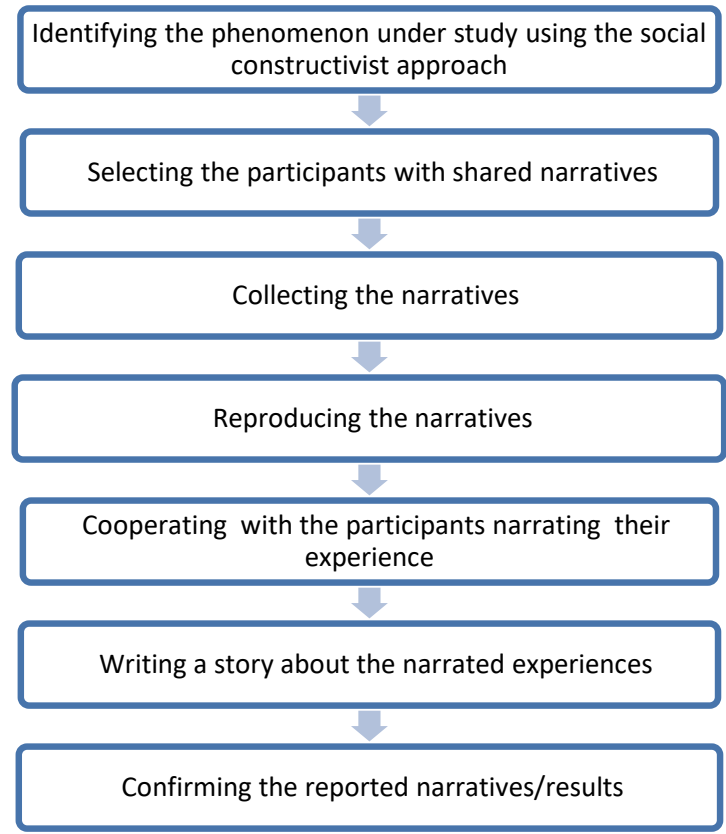

Figure 1. The steps taken to conduct the study

Client- Centered Nursing Care

\section{The second theme: Joint religious beliefs}

A couple's shared ideological and religious beliefs are crucial to their successful life. The participants in this study pointed out that this issue was important for them before marriage and considered it to be one of the main factors affecting mate selection. One of the participants stated, "Before I got married, I talked to her a lot that religious beliefs and morality are very important to me in life. I do not like lying, and as a religious person I emphasize respecting others and not spoiling other people's rights". His wife also stated, "Yes, we tried to have God to be a priority in our life. It is very important for me not to steal other people's properties and live on stolen properties. Of course, we talked a lot about moral and religious issues, and that we both had a lot in common. Religious issues were very important to us and are still one of the priorities of our lives" (couple \#5).

\section{The third theme: Shared socioeconomic positions}

The analysis of the participants' narratives suggested that the couple's consistency in terms of education, economic status, class, belief, personality, and attitudes was very important in mate selection. The couples who were satisfied with their married life believed that they should choose someone as their partner who was compatible with them in terms of social class, culture, education, religious beliefs, and attitudes towards life. One of the male participants stated:
Well, to be honest, my priority was to choose someone as my partner who matched me in terms of beliefs. It was very important for me to choose someone who had shared with me the same cultural, social, political, and ideological views. The other important thing was to match each other in terms of family background. I also think couples who have a realistic expectation of marriage do not have fantasies and irrational emotions about marriage. It is often the case that ambitious people who expect to become successful overnight run into many problems. For example, some couples expect to have a lot in common in the first years of their marital life. Well, it is natural that this does not happen perfectly in the first years.

His wife stated:

Having the minimum job and financial requirements is important for someone who is going to marry. The couple's families need to be at the same level economically, socially, and culturally. When the families differ in these issues, there is a real problem. When I got to know him, I paid close attention to this issue. I had previously rejected a few people because of economic and cultural differences, and I think that having the minimum job and financial requirements is a prerequisite for marriage because the couple may run into problems later (couple \#6). 
Table 1. Demographic data of the study participants

\begin{tabular}{|c|c|c|c|c|c|c|c|}
\hline Couples & Gender & Occupation & Education & $\begin{array}{l}\text { Marriage } \\
\text { Length, } Y\end{array}$ & $\begin{array}{l}\text { Marriage } \\
\text { Age, } Y\end{array}$ & $\begin{array}{l}\text { Current } \\
\text { Age, } Y\end{array}$ & $\begin{array}{l}\text { Number of } \\
\text { Children }\end{array}$ \\
\hline \multirow{3}{*}{1} & Male & Employee & Bachelor's degree & \multirow{3}{*}{14} & 31 & 45 & \multirow{3}{*}{2} \\
\hline & & & & & & & \\
\hline & Female & Housewife & Diploma & & 25 & 39 & \\
\hline \multirow{3}{*}{2} & Male & Employee & Master's degree & \multirow{3}{*}{17} & 27 & 44 & \multirow{3}{*}{2} \\
\hline & & & & & & & \\
\hline & Female & Housewife & Diploma & & 18 & 35 & \\
\hline \multirow{3}{*}{3} & Male & Journalist & Master's degree & \multirow{3}{*}{11} & 25 & 36 & \multirow{3}{*}{2} \\
\hline & & & & & & & \\
\hline & Female & English teacher & Master's degree & & 23 & 34 & \\
\hline \multirow{3}{*}{4} & Male & Employee & Bachelor's degree & \multirow{3}{*}{10} & 26 & 34 & \multirow{3}{*}{2} \\
\hline & & & & & & & \\
\hline & Female & Employee & Bachelor's degree & & 28 & 36 & \\
\hline \multirow{3}{*}{5} & Male & Researcher & Master's degree & \multirow{3}{*}{10} & 25 & 35 & \multirow{3}{*}{1} \\
\hline & & & & & & & \\
\hline & Female & Employee & Master's degree & & 21 & 31 & \\
\hline \multirow{3}{*}{6} & Male & Employee & Master's degree & \multirow{3}{*}{16} & 28 & 44 & \multirow{3}{*}{2} \\
\hline & & & & & & & \\
\hline & Female & Consultant & Bachelor's degree & & 27 & 43 & \\
\hline \multirow{3}{*}{7} & Male & Journalist & Master's degree & \multirow{3}{*}{10} & 30 & 38 & \multirow{3}{*}{2} \\
\hline & & & & & & & \\
\hline & Female & Housewife & Associate's degree & & 26 & 34 & \\
\hline \multirow{3}{*}{8} & Male & Employee & Master's degree & \multirow{3}{*}{10} & 27 & 34 & \multirow{3}{*}{2} \\
\hline & & & & & & & \\
\hline & Female & Employee & Bachelor's degree & & 26 & 33 & \\
\hline \multirow{3}{*}{9} & Male & Employee & Bachelor's degree & & 27 & 37 & \\
\hline & & & & 10 & & & 2 \\
\hline & Female & Housewife & Diploma & & 29 & 38 & \\
\hline & Male & Employee & Master's degree & & 31 & 47 & \\
\hline 10 & & & & 16 & & & 2 \\
\hline & Female & Employee & Bachelor's degree & & 26 & 42 & \\
\hline & Male & Employee & Master's degree & & 20 & 42 & \\
\hline 11 & & & & 23 & & & 4 \\
\hline & Female & Employee & Master's degree & & 18 & 40 & \\
\hline & Male & Dentist & PhD & & 28 & 42 & \\
\hline 12 & & & & 14 & & & 3 \\
\hline & Female & Housewife & Master's degree & & 23 & 37 & \\
\hline & Male & Employee & Master's degree & & 26 & 38 & \\
\hline 13 & & & & 12 & & & 1 \\
\hline & Female & Employee & Bachelor's degree & & 25 & 37 & \\
\hline
\end{tabular}

Client- Centered Nursing Care

The fourth theme: Mutual respect and understanding

One of the points frequently observed in the participants' stories was to have a mutual respect and understanding of marital relationships. For example, one of the male participants stated:
Establishing boundaries in relationships is very important. Besides, the couple should keep distance and privacy from paternal or main families and not allow them to interfere in conflicts and problems between couples. For example, when we first met and decided to get married, we did not want our problems to be solved outside the family, that is, we decided that we had to solve ev- 
erything ourselves, even our financial problems so that other people do not think that we need money. We also tried to respect each other and solve our problems by understanding each other.

The wife also added:

People who want to marry should take the time to get to know each other and to respect and understand each other. People who have such an attitude in choosing a spouse, despite the difficulties, take the time to get to know each other. My husband and I respected cultural issues and we met and talked after office hours. We talked for about 200 hours face-to-face and on the phone. The problem is that some people do not pay any attention to mutual respect and understanding before marriage. Someone who does not respect the other party or partner before marriage, he/she gets worse in his/her behavior after marriage (couple \#10).

\section{Discussion}

The analysis of the participants' narratives showed that the couples believed that four main themes, including spouse personality traits, shared religious beliefs, shared socioeconomic positions, and mutual respect and understanding were involved in their satisfaction with marital life. This finding was consistent with the results of other studies on couples' long-term marital satisfaction. For example, Branham examined the men's definition of their romantic relationship with their partner and found that paying attention to the goals and expectations of the other party and having a strong relationship with a partner improved couples' romantic relationships (Branham 2020). Also, the couple's shared happiness and positive memories and remembering them can contribute to higher marital satisfaction (Alea \& Vick 2010). However, other personality traits are very prominent in how couples lead their relationship from "me" to "we" and have a lot in common. For instance, Chircop examined young married couples' experiences towards the co-construction of couplehood. The results revealed that five superordinate themes, including emotional connectedness, relational security, the negotiation of balance between togetherness and separateness, mutual active participation, and boundary-making enhanced the couple's co-construction of a unified couple identity (Chircop 2017).

Previous studies have also shown that other factors affecting long-term marital satisfaction include commitment (Guilbault \& Philiphe 2017), sexual desire, longing for each other (Beaudoin et al., 2020), personality traits, the understanding of the relationships in marital life
(Bühler \& Dunlop 2019), support, love for the partner, embodying a great common goal in life (Gildersleeve 2015), and flexibility in life (Bachand \& Carson 2001).

Moreover, a phenomenological study examined the life experiences of couples who were married for 40 years and showed that factors, such as "being together", "children/grandchildren", "attitude to commitment", "mutual respect", "humor in life", "compatibility", "supportiveness", and "sense of security" were effective in having long-term marital satisfaction (Nimtz 2011).

Sorokowski et al. examined marital satisfaction factors in 33 Western and Eastern countries and concluded that gender, age, the duration of marriage, religiosity/religion, the number of children, economic/social status and class, education, and individualism/collectivism were the main predictors of marital satisfaction (Sorokowski et al., 2017). For example, men are more satisfied with their marriage than women, in Western and non-Western cultures (McCoy et al., 2017). However, cultural differences and variables must be taken into account. Although no conclusive finding was observed for age, it should be considered as a predictor of marital satisfaction in terms of the duration of the marriage. The length of marriage is related to marital satisfaction. The effect of the length of marriage on marital satisfaction is U-shaped, indicating that it decreases at first and increases after a while. Nevertheless, the effect of this variable varies by the culture. Also, religion is strongly associated with various values and norms and therefore associated with marital satisfaction. Furthermore, as a very culturally dependent factor, the number of children is related to marital satisfaction. Besides, low income or economic poverty is a serious threat to the quality and stability of marriage (Sorokowski et al., 2017). People with better jobs and higher socioeconomic status report higher marital satisfaction (Khodabakhshi-Koolaee et al., 2017). Atari, Chaudhary and Al-Shawaf (2020) showed that spouse personality traits, such as kindness and trustworthiness, and also the lack of differences in the socioeconomic status of families were the most important factors associated with mate preferences in three countries of Iran, Pakistan, and Turkey with predominantly Muslim populations (Atari, Chaudhary \& Al-Shawaf 2020).

The present study was conducted with some limitations. One of the limitations is the very nature of narrative research. The stories told in the interviews reflected the participants' experiences and their cultural backgrounds, and therefore, lacked objectivity. Besides, the participants were selected through the purposive sampling method from couples referring to the family 
entertainment centers of health houses affiliated with Qom Municipality. At last, all of our participants had a diploma or higher academic degrees (because only they agreed to participate in the study); this reduces the transmission power of the findings.

The findings of this study include some implications for premarital education and counseling, couples' counselors and therapists, preparing and informing marriage applicants about the importance of the role of mate selection and personality traits, and helping them to better understand their future spouse.

\section{Conclusion}

In the present study, couples with long-term marital satisfaction highlighted the important role of mate selection in their narratives. They also believed that factors, including spouse personality traits, shared religious beliefs, shared socioeconomic positions, and mutual respect and understanding were effective in long-term marital satisfaction and stable marital life.

\section{Ethical Considerations}

\section{Compliance with ethical guidelines}

To comply with ethical considerations, written informed consent was obtained from the participants to allow conducting and recording the interviews. Besides, the participants were assured that their personal information would be kept confidential. After analyzing the data, the recorded files of the interviews were deleted (at the request of the participants). This research project was registered in the Bioethics Committee of Islamic Azad University, Tehran Science and Research Branch, with the Code of IR.IAU.SRB.REC.1398.069.

\section{Funding}

This study was extracted from $\mathrm{PhD}$. dissertation of first author, at the Islamic Azad University, Science and Research Branch.

\section{Authors' contributions}

All authors equally contributed to preparing this article.

\section{Conflict of interest}

The authors declared no conflict of interest.

\section{Acknowledgments}

The authors sincerely appreciate the couples and the staff and managers of the Municipality of Qom for their help in carrying out this research.

\section{References}

Abdullah, H. S., 2018. Gender differences in mate selection criteria among Malaysian undergraduate students. Sarjana, 26(2) pp. 33-50. https://ejournal.um.edu.my/index.php/SARJANA/article/view/10465

Alea, N., Singer, J. A., \& Labunko, B., 2015. “We-ness" in relationship-defining memories and marital satisfaction. In Cou Dordrecht, Springer, pp. 163-177. [DOI:10.1007/978-94-017-9909-6_9]

Alea, N., \& Vick, S. C., 2010. The first sight of love: Relationshipdefining memories and marital satisfaction across adulthood Memory, 18(7), pp. 730-742. [DOI:10.1080/09658211.2010.5064 43] [PMID]

Arif, N., \& Fatima, I., 2015. Marital satisfaction in different types of marriage. Pakistan Journal of Social and Clinical Psychol ogy, 13(1), pp. 36-40. https://gcu.edu.pk/wp-content/uploads/2020/04/pjscp20151-5.pdf

Atari, M., Chaudhary, N., \& Al-Shawaf, L., 2020. Mate preferences in three Muslim-majority countries: sex differences and personality correlates. Social Psychological and Personality Science, 11(4), pp. 533-45. [DOI:10.1177/1948550619866187]

Bachand, L. L., \& Caron, S. L., 2001. Ties that bind: A qualitative study of happy long-term marriages. Contemporary Family Therapy, 23(1), pp. 105-21. [DOI:10.1023/A:1007828317271]

Beaudoin, J., et al., 2020. The role of sexual passion in romantic relationship functioning: A dyadic analysis. Journal of Social and Personal Relationships, p. 0265407520972191. [DOI:10.1177/0265407520972191]

Branham, S., 2020. A Qualitative exploration of romantic relationships: Perspectives of educated men in emerging adulthood (PhD. dissertation), Minnesota, Capella University. https:/ / search.proquest.com/openview/603ceb0fe4e22b9f4 0d5183c81c60c81/1?pq-origsite $=$ gscholar \&cbl=18750\&diss $=y$

Brooks, J. E., \& Moore, D. D., 2020. African American young adult women's stories about love: What $\mathrm{i}$ want in a longterm partner. Journal of Black Studies, 51(4), pp. 295-314 [DOI:10.1177/0021934720908487]

Buss, D. M., et al., 2001. A half-century of mate preferences: The cultural evolution of values. Journal of Marriage and Family, 63(2), pp. 491-503. [DOI:10.1111/j.1741-3737.2001.00491.x]

Bühler, J. L., \& Dunlop, W. L., 2019. The narrative identity approach and romantic relationships. Social and Personality Psychology Compass, 13(4), p. e12447. [DOI:10.1111/spc3.12447]

Creswell, J. W., \& Báez, J. C., 2020. 30 essential skills for the qualitative researcher. New York, Sage Publications. https:// us.sagepub.com/en-us/nam/30-essential-skills-for-the-qualitative-researcher/book237360 
Cheung, M., 2008. The resilience of older immigrant couples: Long-term marital satisfaction as a protective factor. Journal of Couple \& Relationship Therapy, 7(1), pp. 19-38. [DOI:10.1080/15332690802129697]

Chircop, Y. R., 2017. From "Me" to "We": The journey of young married couples' experience towards the co-construction of couplehood. IFT-Malta (Institute of Family Therapy Malta), http:// www.ift-malta.com/wp-content/uploads/2017/12/YanicaChircop.pdf

Gee, J. P., 1991. A linguistic approach to narrative. Journal of narrative and Life History, 1(1), pp. 15-39. [DOI:10.1075/ jnlh.1.1.03ali]

Gildersleeve, S., 2015. Capturing the" We-ness" of happy couples through narrative analysis. New London, CT Connecticut College Digital Commons @ Connecticut College. https://core. ac.uk/download/pdf/46707038.pdf

Guilbault, V., \& Philippe, F. L., 2017. Commitment in romantic relationships as a function of partners' encoding of important couple-related memories. Memory, 25(5), pp. 595-606. [DOI:10. 1080/09658211.2016.1197943] [PMID]

Guner, N., Kulikova, Y., \& Llull, J., 2017. Marriage and health: Selection, protection, and assortative mating. European Economic Review, 104, pp. 138-66. [DOI:10.1016/j.euroecorev.2018.02.005] [PMID] [PMCID]

Holland, R., 2009. Perceptions of mate selection for marriage among African American, college-educated, single mothers. Journal of Counseling \& Development, 87(2), pp. 170-8. [DOI:10.1002/j.1556-6678.2009.tb00564.x]

Khodabakhshi Koolaee, A., et al., 2015. The relationship between employment of male doctors with marital satisfaction and life quality of their wives. Iranian Journal of Nursing Research, 10(3), pp. 89-99. [DOI:10.32598/jccnc.2.1.3]

Igbo, H. I., Grace, A. R., \& Christiana, E. O., 2015. Relationship between the duration of the marriage, personality trait, gender, and conflict resolution strategies of spouses. ProcediaSocial and Behavioral Sciences, 190, pp. 490-6. [DOI:10.1016/j. sbspro.2015.05.032]

Lehrer, E. L., \& Chen, Y., 2013. Delayed entry into first marriage and marital stability: Further evidence on the Becker-LandesMichael hypothesis. Demographic Research, 29, pp. 521-42. [DOI:10.4054/DemRes.2013.29.20]

Maciver, J. E., \& Dimkpa, D. I., 2012. Factors influencing marital stability. Mediterranean Journal of Social Sciences, 3(1), pp. 437-44.

McCoy, A., Rauer, A., \& Sabey, A., 2017. The Meta marriage: Links between older Couples' relationship narratives and marital satisfaction. Family Process, 56(4), pp. 900-14. [DOI:10.1111/famp.12217] [PMID]

McNulty, J. K., \& Karney, B. R., 2002. Expectancy confirmation in appraisals of marital interactions. Personality and Social Psychology Bulletin, 28(6), pp. 764-75. [DOI:10.1177/0146167202289006]

Memarzadeh, M., Khodabakhshi-Koolaee, A., \& Khatiban, M., 2017. The Effect of training the nine enneagram personality types on spouse selection criteria and marital attitude of single girls. Journal of Education and Community Health, 3(4), pp. 24-30. [DOI:10.21859/jech.3.4.24]

Neustadter, S., 2011. Transpersonal mate selection: An investigation of spiritual and extraordinary factors that influence the decision to marry one's partner. California, Institute of Transpersonal Psychology. https://sarahneustadter.com/ wp-content/uploads/2018/11/Neustadter-Dissertation.pdf

Nimtz, M. A., 2011. Satisfaction and contributing factors in satisfying long-term marriage: A phenomenological study. Lynchburg, Liberty University. https://digitalcommons.liberty.edu/cgi/ viewcontent.cgi?referer=https://scholar.google.com/\&https redir $=1 \&$ article $=1496 \&$ context $=$ doctoral

Polkinghorne, D. E., 2007. Validity issues in narrative research. Qualitative Inquiry, 13, p. 471486. [DOI:10.1177/1077800406297670]

Rodríguez-González, M., et al., 2016. Differentiation of self, mate selection, and marital adjustment: Validity of postulates of Bowen theory in a Spanish sample. The American Journal of Family Therapy, 44(1), pp. 11-23. [DOI:10.1080/01926187.2015. 1099415]

Sorokowski, P., et al., 2017. Marital satisfaction, sex, age, marriage duration, religion, number of children, economic status, education, and collectivistic values: Data from 33 countries. Frontiers in Psychology, 8, p. 1199. [DOI:10.3389/fpsyg.2017.01728] [PMID] [PMCID]

Valentine, K. A., et al., 2020. Mate preferences for warmthtrustworthiness predict romantic attraction in the early stages of mate selection and satisfaction in ongoing relationships. Personality and Social Psychology Bulletin, 46(2), pp. 298-311. [DOI:10.1177/0146167219855048] [PMID]

Wells, K., 2011. Narrative inquiry. New York, Oxford University Press. [DOI:10.1093/acprof:oso/9780195385793.001.0001]

Wong, S., \& Goodwin, R., 2009. Experiencing marital satisfaction across three cultures: A qualitative study. Journal of Social and Personal Relationships, 26(8), pp. 1011-28. [DOI:10.1177/0265407509347938]

Zaheri, F., et al., 2016. Effective factors in marital satisfaction in the perspective of Iranian women and men: A systematic review. Electronic Physician, 8(12), p. 3369. [DOI:10.19082/3369] [PMID] [PMCID] 
This Page Intentionally Left Blank 